\title{
DETECCIÓN DE RICKETTSIA SP. EN LA GARRAPATA CAFÉ DEL PERRO RHIPICEPHALUS SANGUINEUS (ACARI: IXODIDAE) EN MATAMOROS, COAHUILA, MÉXICO
}

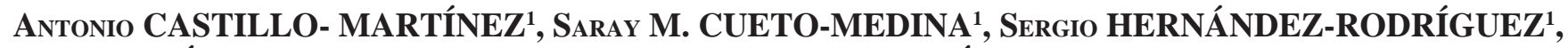 Miguel Ángel GALlegos-ROBLES ${ }^{2}$, MARÍa Teresa VALDÉS-PEREZGASGA ${ }^{1}$, Francisco Javier SÁNCHEZ-RAMOS $^{1 *}$ \& ALdo I. ORTEGA-MORALES ${ }^{1}$}

\author{
${ }^{1}$ Universidad Autónoma Agraria Antonio Narro Unidad Laguna, Periférico Raúl López Sánchez CP. 27054. \\ <acm_sultan@hotmail.com>; <sary_cueto@hotmail.com>, <sergiohr39@hotmail.com>; <cebolla_55@hotmail. \\ com>; <*fjsr1958@hotmail.com>; <agrortega@hotmail.com>. \\ ${ }^{2}$ Facultad de Agricultura y Zootecnia, Universidad Juárez del Estado de Durango, Km. 35 Carretera Gómez \\ Palacio- Tlahualilo. Domicilio Conocido, Venecia, Gómez Palacio, Durango, México. CP 35170. < garoma64@ \\ hotmail.com>
}

Recibido: 26/06/2014; aceptado: 23/10/2014

Castillo-Martínez, A., Cueto-Medina, S. M.,Hernández-Rodríguez, S., Gallegos-Robles, M. A., Valdes-Perezgasga, M. T., Sánchez-Ramos, F. J. \& Ortega- Morales, A. I. 2015. Detección de Rickettsia sp. en la garrapata café del perro Rhipicephalus sanguineus (Acari: Ixodidae) en Matamoros, Coahuila, México. Acta Zoológica Mexicana (n. s.), 31(1): 80-83.

RESUMEN. Se colectaron al azar 217 garrapatas sobre 72 perros domésticos en el municipio de Matamoros, Coahuila, éstas fueron identificadas como Rhipicephalus sanguineus Latreille. Con la intención de determinar la presencia de la bacteria (Rickettsia sp.) causante de la fiebre manchada de las Montañas Rocosas (FMMR), las garrapatas se agruparon en muestras $(n=100)$ para pruebas moleculares, las hembras repletas de sangre fueron diseccionadas para obtener el contenido estomacal y los órganos internos. Las ninfas y los machos se maceraron para exponer el contenido interno. Empleando la técnica de CTAB se obtuvo ADN de cada pool, el cual fue sometido a ensayos de PCR para amplificar el gen gltA para la detección de Rickettsias. Se reporta la presencia de Rickettsia sp. en una frecuencia del 4\% (4). El presente trabajo constituye el primer registro del agente causal de la fiebre manchada Rickettsia sp. en órganos internos de la garrapata café del perro, $R$. sanguineus a través de técnicas moleculares en el municipio de Matamoros, Coahuila, región endémica de esta enfermedad.

Palabras clave: Rickettsia spp., PCR, garrapatas, gltA.

\section{INTRODUCCIÓN}

La garrapata café del perro Rhipicephalus sanguineus puede ser vector de Rickettsia rickettsii, agente causante de la fiebre manchada de las Montañas Rocosas (FMMR), cuando se alimentan de la sangre de animales domésticos y silvestres, además del hombre (Jawetz \& Adelberg 1996; Quinn \& Markey 2003). Los hospederos se infectan cuando las garrapatas infectivas inoculan Rickettsias al torrente sanguíneo junto con la saliva que regurgitan. El contacto con los aerosoles que se generan con garrapatas aplastadas o con animales infectados de Rickettsias, pueden ser medios de infección cuando se exponen heridas externas u otras laceraciones (Merchant
Castillo-Martínez, A., Cueto-Medina, S. M., HernándezRodríguez, S., Gallegos-Robles, M. A., Valdes-Perezgasga, M. T., Sánchez-Ramos, F. J. \& Ortega- Morales, A. I. 2015. Detection of Rickettsia sp. in brown dog tick Rhipicephalus sanguineus (Acari: Ixodidae) of Matamoros, Coahuila, Mexico. Acta Zoológica Mexicana (n. s.), 31(1): 80-83.

ABSTRACT. Two hundred and seventeen ticks randomly collected from seventy two domestic dogs, in Matamoros municipality, Coahuila, these were taxonomically identified as Rhipicephalus sanguineus Latreille. In order to determine Rickettsia sp. presence in ticks these were grouped in 100 pools for molecular testing. Engorged female ticks were dissected to obtain pellets containing internal organs and haemolymph. Nymphs and males were triturated for exposing internal contents from which DNA was extracted by the CTAB technique and subjected to PCR to amplify the gltA gene for detection of Rickettsia. The frequency for Rickettsia sp. was $4 \%$ (4). The present work constitutes the first record of the causative agent of the spotted fever Rickettsia sp. in internal organs of brown $\operatorname{dog}$ tick $R$. sanguineus through molecular techniques in Matamoros municipality, Coahuila, endemic region of this disease.

Key words: Rickettsia spp., PCR, ticks, gltA.

\& Racker 1980). En México, América Central y Sudamérica la Fiebre Manchada es considerada una enfermedad reemergente (Hidalgo et al. 2007) y que ocasiona mayor morbilidad en el norte de México (SINAVE 2013), donde el vector principal de $R$. rickettsii es $R$. sanguineus (Bustamante \& Varela 1946, Hoffmann 1962, Labruna et al. 2011).

En la región política conocida como Comarca Lagunera (CL) en los estados de Coahuila y Durango existen las condiciones ambientales, geográficas, demográficas, epidemiológicas y socioeconómicas (marginación y pobreza) para el establecimiento de poblaciones de garrapatas, en donde se han reportado grandes números de ellas en reportes previos (DGSA-SAGAR 1996). En la Comar- 
ca Lagunera los casos de Fiebre Manchada se han atribuido a $R$. sanguineus como vector de $R$. rickettsii (Labruna et al. 2011). En el municipio de Matamoros, Coahuila existen viviendas construidas de adobe con piso de tierra y los habitantes conviven con gran cantidad de perros (NOM-EM-001-SSA2 1999). En 1945, se notificaron casos humanos positivos a fiebre manchada en el Ejido Jimulco (Torreón, Coah.), en 1946 se aislaron dos cepas de Rickettsia en garrapatas $R$. sanguineus provenientes del Ejido Granada (Matamoros, Coahuila) y del Ejido Zaragoza (Torreón, Coah.); se analizaron muestras de sangre humana y suero de perro que resultaron positivos a Fiebre Manchada (Bustamante et al. 1946). Desde 1975 al año 2007, se registraron 115 casos de Fiebre Manchada en Torreón (De Lara \& Cárdenas 2008); dentro del cual están inmersos los casos del periodo 1990-2000, donde se reportaron 34 casos para la Comarca Lagunera. En el año 2011 se presentaron siete casos en el estado de Coahuila, de los cuales dos sucedieron en Torreón; durante los años 2012-2013 se documentaron 75 y 46 casos humanos respectivamente en la CL, donde uno de ellos se presentó en el ejido La Atalaya (SINAVE 2013; 2014).

\section{MATERIALES Y MÉTODOS}

La colecta de garrapatas se realizó en La Atalaya y el Cambio pertenecientes al municipio de Matamoros, Coahuila; el cual está ubicado entre los paralelos $25^{\circ} 23^{\prime}$ y $25^{\circ} 48^{\prime}$ de latitud norte, con los meridianos $103^{\circ} 23^{\prime}$ y $103^{\circ} 03^{\prime}$ de longitud oeste. Con una elevación media de 1,110 metros sobre el nivel del mar (INEGI 2014). Las garrapatas en todos sus estados de vida a excepción del huevo, fueron colectadas durante los meses de junio a noviembre del 2013. Un total de 217 garrapatas fueron colectadas directamente sobre 72 perros domésticos, las cuales se obtuvieron del hospedero evitando el desprendimiento del gnatosoma. Las garrapatas se preservaron en etanol al $70 \%$ en viales de $2 \mathrm{ml}$. Estas fueron transportadas al Laboratorio de Biología Molecular del Departamento de Parasitología de la Universidad Autónoma Agraria Antonio Narro Unidad Laguna, en donde se lavaron con agua ultrapura y posteriormente se conservaron en etanol al $96 \%$ en viales de $1.5 \mathrm{ml}$. Todos los especímenes fueron consistentes con la descripción de $R$. sanguineus (Walker et al. 2000). Para exponer el contenido interno de cada garrapata, se diseccionaron con tijeras Iris de disección (BioQuip No. 4715) previamente esterilizadas realizando un corte dorsoventral desde la base de los palpos hasta la parte posterior del idiosoma. Una vez expuesto el contenido interno, se retiró del exoesqueleto sujetándolo con pinzas entomológicas (BioQuip No. 4531) para colocarlo en un vial de $1.5 \mathrm{ml}$ en seco. El contenido intestinal, así como los machos e inmaduros se maceraron individualmente usando pistilos de maceración de tejido (Thomas Scientific No. TS0913X70) en un medio líquido de agua milli-Q (Life Invitrogen, USA). Los productos macerados se agruparon por muestras $(n=100)$ a razón de 1 muestra $=1 q$ adulta ( 1 contenido intestinal a repleción, sin exoesqueleto); $2 \hat{\gamma}$ adultos completos (incluyendo exoesqueleto); 4 q / $\widehat{o}$ especímenes inmaduros completos incluyendo exoesqueleto (Cuadro 1).

Pruebas moleculares. La extracción de ADN se realizó siguiendo la técnica de Cetyl Trimethyl Ammonium Bromide o CTAB (Doyle \& Doyle 1987), el cual fue evaluado en calidad y cantidad por medio de nanodrop (Thermo Scientific NanoDrop 2000). El ADN obtenido se resuspendió en $20 \mu$ l de buffer TE 1X [400 $\mu$ l EDTA (Life Invitrogen, USA) + $4 \mathrm{ml}$ Tris Base (Bio Basic Canada Inc.)] y se almacenó a $-20^{\circ} \mathrm{C}$. Para los ensayos PCR se usó un primer genérico para Ricketssia spp: Forward: RpCS.877p GGGGGCCTGCTCACGGCGG, Reverse: RpCS.1258n ATTGCAAAAAGTACAGTGAACA (Regnery et al. 1991), el cual amplifica en un rango de 380-397 pb el gen gltA de la citrato sintasa (Wood et al. 1987). Las reacciones de PCR contuvieron 20 pmoles de los iniciadores dNTP's (Life Invitrogen, USA) a una concentración de $1.5 \mathrm{mM}, 1.25 \mathrm{U}$ de Taq DNA polimerasa (Life Invitrogen, USA), $3 \mu$ de Buffer 10X (200 mM Tris-HCl pH 8.4 Bio Basic Canada Inc.), 500 mg KCl, 10-200 ng de ADN templado y Agua Mili-Q (Life Invitrogen, USA) para completar un volumen de $100 \mu \mathrm{l}$. Para el gen gltA, (Cuadro 2), las condiciones del termociclador Select Cycler II (Select BioProducts, USA) fueron: un ciclo a $95{ }^{\circ} \mathrm{C}$ (1 minuto), 35 ciclos de tres pasos: desnaturalización a $95^{\circ} \mathrm{C}$ (20 segundos), alineación de iniciadores a $48^{\circ} \mathrm{C}$ (30 segundos), extensión a $60{ }^{\circ} \mathrm{C}$ (2 minutos) y extensión final a $72{ }^{\circ} \mathrm{C}$ (1 min). Los productos de PCR, el control positivo y el marcador de peso molecular hyperladder 100-pb (Bioline, USA), fueron visualizados en gel de agarosa al $1 \%$ y teñidos con Gel Red (Biotium TM, USA); la imagen de

Cuadro 1. Garrapatas recolectadas en dos localidades del Municipio de Matamoros, Coahuila.

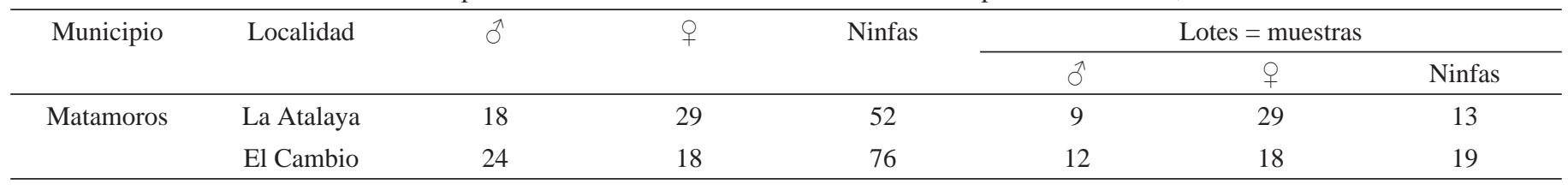


Cuadro 2. Primers utilizados (Regnery et al. 1991).

\begin{tabular}{cr}
\hline Gen & \multicolumn{1}{c}{ Primers } \\
\hline gltA & RpCS.877p: 5' GGGGGCCTGCTCACGGCGG 3' \\
& RpCS.1258n: 5' ATTGCAAAAAGTACAGTGAACA 3' \\
\hline
\end{tabular}

los productos se capturó en un fotodocumentador MiniBis Pro (Bio-Imaging Systems).

\section{RESULTADOS}

Se obtuvieron 4 muestras positivas para Rickettsia sp., en donde el 4\% (4/100) de las muestras correspondieron a garrapatas hembras (Cuadro 3). La presencia de Rickettsia sp. en los órganos internos macerados de las muestras de garrapatas fue determinada mediante PCR amplificando los genes gltA derivados de los primers RpCS.877p y RpCS.1258n con un rango de 380-397 pb (Fig. 1).

\section{DISCUSIÓN}

En las áreas rurales del municipio de Matamoros, Coahuila, México; la especie de garrapata más abundante y frecuente en perros domésticos es la garrapata café del perro $R$. sanguineus y en menor proporción las garrapatas del género Otobius, postulando la hipótesis que esta especie de garrapata podría estar involucrada en el ciclo de transmisión de la enfermedad (Bustamante \& Varela 1946, Hoffmann 1962, Labruna et al. 2011) debido al aislamiento de una cepa de rickettsia en $R$. sanguineus colectada en el Ejido Granada (Bustamante et al. 1946), comunidad que se ubica a $1.5 \mathrm{~km}$ del Ejido La Atalaya (INEGI 2014), donde recientemente se presentó un caso humano confirmado de Fiebre Manchada (SINAVE 2013), asociado a la garrapata antes mencionada.

$R$. sanguineus es vector de bacterias, entre ellas las rickettsias (Bruning 1996), en este estudio se extrajeron y maceraron los órganos internos de las garrapatas y con el método PCR se detectaron cuatro muestras positivas al género Rickettsia sp. mediante la amplificación por PCR del gen gltA, lo cual se consigna a lo reportado por Fernández (2003) quien utilizó los primers de Regnery et al. (1991); pero con diferencias en el método de maceración y extracción de ADN utilizadas en este estudio, los cua-

Cuadro 3. Muestras de garrapatas Rhipicephalus sanguineus procesadas por PCR para la detección de Rickettsia sp.

\begin{tabular}{lccc}
\hline Localidad & $\begin{array}{c}\text { Número de } \\
\text { muestras }\end{array}$ & $\begin{array}{c}\text { Muestras } \\
\text { positivas }\end{array}$ & $\begin{array}{c}\text { Muestras } \\
\text { negativas }\end{array}$ \\
\hline La Atalaya & 50 & $4(8 \%)$ & $46(92 \%)$ \\
El Cambio & 50 & $0(0 \%)$ & $50(100 \%)$ \\
\hline
\end{tabular}

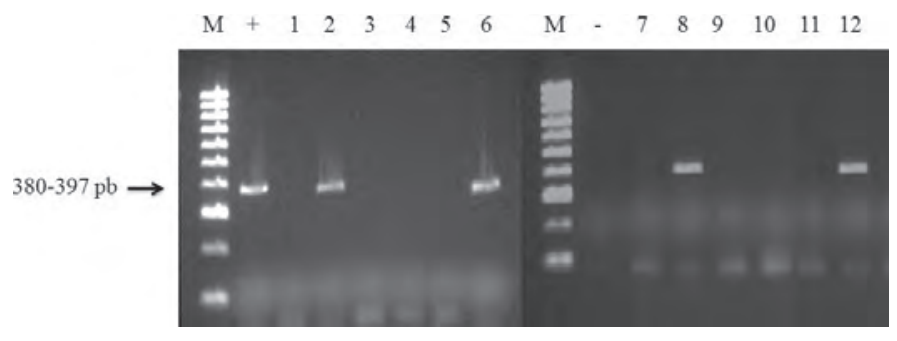

Figura 1. Productos de PCR del gen gltA de Rickettsia a partir de ADN obtenido de garrapatas A. Líneas 1-12 = garrapatas colectadas en ejido La Atalaya. $\mathrm{M}$ = marcador molecular 100-1000 pb, + $=$ Control positivo, $-=$ Control negativo sin ADN. Fragmento observado de 380-397 pb.

les permitieron una mejor manipulación de los órganos internos de las garrapatas y redujeron la cantidad de sustancias inhibidoras de la PCR. Los resultados concuerdan con Demma et al. (2005) quien menciona que no todas las especies de garrapatas son vectores del patógeno y sólo del 1 al 5\% están infectados por rickettsias. Así mismo el área rural concuerda con las características descritas por DGSA-SAGAR (1996) quien refiere a la CL como una zona con las condiciones ambientales para que el vector y el patógeno se desarrollen y permanezcan en el área semidesértica, donde los habitantes conviven con gran cantidad de perros en viviendas construidas de adobe con piso de tierra.

\section{LITERATURA CITADA}

Bruning, A. 1996. Equine piroplasmosis an update on diagnosis, treatment and prevention. British Veterinary Journal, 152: 139-151.

Bustamante, M. E., Varela, G. \& Ortiz-Mariotte, C. 1946. Estudios de fiebre manchada en México. Fiebre manchada en la Laguna. Revista Instituto de Salubridad y Enfermedades Tropicales, 7: 3948.

Bustamante, M. G. \& Varela, G. 1946. Estudios de Fiebre Manchada en México: Hallazgo de Amblyomma cajennense naturalmente infectado, en Veracruz. Revista Instituto de Salubridad y Enfermedades Tropicales, 7: 75-78.

De Lara, H. J. \& Cárdenas, B. R. 2008. Fiebre manchada de las Montañas Rocosas en pediatría. Revisión clínica de una serie de 115 casos. Revista de enfermedades infecciosas en pediatría, 22: 4-9.

Demma, L. J., Traeger, M. S., Nicholson, W. L., Paddock, C. D., Blau, D. M., Eremeeva, M. E., Dasch, G. A., Levin, M. L., Singleton, J., Zaki S. R., Cheek, J. E., Swerdlow, D. L. \& McQuiston, J. H. 2005. Rocky Mountain spotted fever from an unexpected tick vector in Arizona. New England Journal of Medicine, 353: 587-594.

Dirección General de Salud Animal: DGSA-SAGAR. 1996. Manual de identificación de las especies de garrapatas de importancia en México del Centro nacional de servicios de constatación de la Comisión Nacional de Sanidad Agropecuaria. [En línea] http://www.senasica.gob.mx/?id = 2803. [Fecha de consulta 6/Enero/2014]. 
Doyle, J. J. \& Doyle, J. L. 1987. A rapid DNA isolation procedure for small quantities of fresh leaf tissue. Phytochemical Bulletin, 19: 11-15.

Fernández, S. P. 2003. Garrapatas que parasitan a las personas en Castilla y León, determinación por serología de su parasitismo y detección molecular de los patógenos que albergan. Tesis doctoral. Universidad de Salamanca. 296 pp.

Hidalgo, M., Orejuela, L., Fuya, P., Carrillo, P., Hernández, J. \& Parra, E. 2007. Rocky Mountain spotted fever, Colombia. Emerging Infectious Diseases, 13: 1058-1060.

Hoffman, A. 1962. Monografia de los Ixodoidea de Mexico: parte I. Revista de la Sociedad Mexicana de Historia Natural, 23: 191 pp.

Instituto Nacional de Estadística y Geografía (INEGI). 2014. Información Nacional por Entidad Federativa y Municipios. [En línea] http://www.inegi.org.mx/sistemas/mexicocifras/default.aspx. [Fecha de consulta 19/Febrero/2014].

Jawetz, E. M. \& Adelberg, E. 1996. Microbiología clínica. 15ª Manual moderno. México, D.F. 783 pp.

Labruna, M., Ogrzewalska M., Soares, J., Martins, T., Soares, H., Moraes-Filho, J., Nieri-Bastos, F., Almeida, A. \& Pinter, A. 2011. Experimental Infection of Ticks with $R$. rickettsii. Emerging Infectious Diseases, 17: 829-834.

Merchant, I. A. \& Racker, R. A. 1980. Bacteriología y virología Veterinarias. $3^{\text {a }}$. Acribia. Zaragoza, España. pp. 517-522.
NOM-EM-001-SSA2. 1999. NORMA Oficial Mexicana de Emergencia NOM-EM-001-SSA2-1999, Para la vigilancia, prevención y control de enfermedades transmitidas por vector. Diario Oficial de la Federación. México, D.F. 47 pp.Quinn, P. J. \& B. K. Markey, 2003. Concise review of veterinary microbiology. $1^{\text {a }}$. Blackwell Publishing. Oxford, UK. pp. 133-135.

Regnery, R. L., Spruill, C. L. \& Plikatys, B. D. 1991. Genotypic identification of Rickettsiae and estimation of intraespecies sequence divergence for portions of two rickettsial genes. Journal Bacteriology, 173: 1576-1589.

Sistema Nacional de Vigilancia Epidemiológica (SINAVE). 2014. Anuarios de Morbilidad: Fiebre Manchada. [En línea] http://www. epidemiologia.salud.gob.mx/anuario/ html/anuarios.html. [Fecha de consulta 19/ mayo/ 2014].

Sistema Nacional de Vigilancia Epidemiológica (SINAVE). 2013. Casos de rickettsiosis en la Jurisdicción Sanitaria No. 6 de Torreón, Coahuila. [En línea] http://www.epidemiologia.salud.gob. $\mathrm{mx} /$ anuario/html/anuarios.html. [Fecha de consulta 19/ Febrero/ 2014].

Walker, J., Keirans, J. \& Horak, I. 2000. The genus Rhipicephalus (Acari: Ixodidae). A guide to the brown ticks of the world. $1^{\mathrm{a}}$. Cambridge University. Cambridge, UK. 628 pp.

Wood, D. O., Williamson, L. R., Winkler, H. H. \& Krause, D. C. 1987. Nucleotide sequence of the Rickettsia prowazekii citrate synthase gene. Journal of Bacteriology, 169: 3564-3572. 